\title{
Latinoamérica en la trama del Diseño. Entre la utopía y la realidad
}

Gustavo Valdés de León *

\begin{abstract}
Resumen / Latinoamérica en la trama del Diseño. Entre la utopía y la realidad
En el ensayo de Gustavo Valdés de León se realiza un profundo análisis de las interrelaciones teóricas y pragmáticas del Diseño como disciplina emblemática de la Modernidad con la realidad -histórica, económica, cultural y política- de Latinoamérica. Para armar esta idea su autor realiza la operación de desarmar metafóricamente una gran caja llena de conceptos que es necesario comprender en profundidad para llegar a pensar en el diseño latinoamericano. Por este motivo, e intentando presentar en todo momento un recorrido por el diseño de América latina, hace referencia al diseño en sí, a Latinoamérica, su nombre y su historia, la relación entre resistencia e hibridación, como se pasa de una etapa de resistencia a otra caracterizada por la imitación.
\end{abstract}

\section{Palabras clave}

Diseño - identidad - Latinoamérica.

\section{Summary / Latin america in the plot of Design. Between utopia and reality}

The essay of Gustavo Valdés de León develops a deep analysis of the theoretical and pragmatic interrelations of Design like emblematic discipline of modernity with the historical, economic, cultural and political reality of Latin America. In order to build this idea the author conducts the metaphorical disassembly of a great full box of concepts that is necessary to understand in depth to get to think about the Latin American design. For this reason, and trying at any moment to display a route by the design of Latin America, it makes reference to design in itself, to Latin America, its name and its history, the relation between resistance and hybridization and the change of a resistance stage into other one characterized by imitation.

\section{Key words}

Design - identity - Latin America.

\section{Resumo / Latinoamerica na trama do Design. Entre a utopia e a realidade}

No ensáio de Gustavo Valdés de León realiza-se uma profunda analisse das interrelações teóricas e pragmáticas do Design como disciplina emblemática da modernidade com a realidade - histórica, económica, cultural e política - de Latinoamérica. Para armar esta idéia seu autor realiza a operação de desarmar metafóricamente uma grande caixa cheia de conceitos que é necessario compreender em profundidade para chegar a pensar no design latinoamericano. Por este motivo, e procurando apressentar em todo momento um percurso pelo design em se, a Latinoamérica, seu nome e sua história, a relação entre resistência e hibridação, como se passa de uma etapa de resistência a outra caracterizada pela imitação.

\section{Palavras clave}

Design - identidade - Latinoamérica.

\footnotetext{
* Diseñador Gráfico (Escuela Panamericana de Arte). Operador Grupal (Escuela Abierta de Psicología Operativa). Profesor regular de la Facultad de Diseño y Comunicación de la Universidad de Palermo. Miembro del Consejo Asesor de la Facultad de Diseño y Comunicación de la Universidad de Palermo. Es docente en otras universidades e instituciones.
} 
Ni la razón ni la ciencia pueden satisfacer completamente la necesidad de infinito que hay en el hombre, solamente el mito tiene el extraño poder de alcanzar las profundidades del ser. José Carlos Mariátegui (citado por Piñeiro Iñíguez, 2006)

Intentar un examen en profundidad de las interrelaciones teóricas y pragmáticas del Diseño como disciplina emblemática de la Modernidad con la realidad -histórica, económica, cultural y política- de Latinoamérica, implica despejar, en primer lugar, los términos en juego para aventar de entrada cualquier equívoco conceptual.

\section{Acerca del Diseño}

El acto de diseñar se define como un proceso de trabajo intelectual y manual que se despliega en el tiempo y cuyo carácter diferencial se concreta en la instancia del proyecto.

Proyectar significa pre-figurar, pre-ver, esto es, imaginar un estado de cosas o un objeto que, por alguna razón hacen falta pero que no existen efectivamente en el momento de iniciarse el acto de diseño y que existirán, de manera inexorable, al finalizar tal proceso, esto es, en un futuro posible, mas o menos próximo, que se verá modificado por la nueva situación o por el nuevo objeto diseñado.

En este sentido, amplio, la facultad de proyectar -como la del Lenguaje- es innata y exclusiva de la especie humana, cuya existencia se realiza en la sucesión temporal e irreversible de presentes continuos -que de inmediato devienen pasado- en una sumatoria aleatoria de eventos que el sujeto, en la medida de sus posibilidades, intenta ordenar como relato coherente producido por él de manera deliberada, aunque, en última instancia, aquella sumatoria no sea mas que efecto de sus reacciones frente a acontecimientos que se le presentan con la rotundez de lo inevitable: el sujeto es su libertad y ésta se despliega en la trama inexorable de la temporalidad, en la elección entre diversas alternativas que determinan cursos de acción mutuamente excluyentes, en los cuales la posibilidad de ballotage-mezclar y dar de nuevo- es inexistente.

A partir de esta condición, irrenunciable y universal, las sociedades humanas o, mejor, los hombres en sociedad se han ido apropiando de la Naturaleza material -que durante muchísimo tiempo no tuvo dueño- compensando su propia precariedad biológica mediante la invención, es decir, mediante el diseño, de artefactos técnicos que, en carácter de prótesis, les permitieron construir, esto es, diseñar, la enorme cantidad de objetos y procesos - de la rueda al rascacielos, del control del fuego a la bomba atómica, de la escritira a la computadora- que constituyen el mundo de la cultura.

Conforme las sociedades se van tornando mas complejas y en particular desde la consolidación del capitalismo como modo de producción, desde la Revolución Industrial -iniciada en el Reino Unido a fines del siglo XVIII y que alcanza su apogeo a partir de la segunda mitad del siglo XIX en algunos países europeos y en los Estados Unidos- la acción de proyectar, el Diseño, se escinde de la acción de producir, asumiendo la primera el carácter de profesión.

En la actualidad la actividad del diseñador, cualquiera sea la especialidad en la que se desempeñe, consiste en proyectar, a partir de un encargo profesional, en el interior de un horizonte estético y tecnológico determinado y siguiendo una metodología racional, que no excluye -o no debería excluir- la emergencia de lo lúdico, productos que cumplirán funciones prácticas o simbólicas, de mayor o menor complejidad operativa y sígnica, que, fabricados de manera industrial, están destinados, bajo la especie de mercancías, a ser consumidos por un mercado determinado.

Si los productos diseñados, producidos y comercializados responden a necesidades reales de los usuarios o si sólo son el resultados de necesidades artificiales inducidas, -o directamente, producidas- gracias al recurso de la Publicidad por la empresas que los fabrican, es una cuestión siempre abierta a la polémica y que excede el propósito de este texto.

Si bien la facultad de proyectar, como ya dijimos, es con-natural a cada sujeto, como condición irrenunciable de su ser-en-elmundo, la acción profesional de diseñar, vinculada necesariamente a procesos industriales de producción, surge como tal en la medida en que las sociedades alcanzan un cierto nivel de desarrollo económico que requiere la figura del diseñador que controle la eficiencia de la producción del artefacto, en términos de función, forma, materialidad, proceso y significación, y garantice, razonablemente, tanto el beneficio económico de la empresa como la satisfacción del usuario.

Ahora bien jexisten en los países latinoamericanos las condiciones -económicas, sociales, culturales y políticas- en las cuales el diseñador, en el sentido antes señalado, cumple en efecto una función socialmente necesaria que lo legitime como tal? Sobre todo tomando en consideración que nuestro concepto del Diseño, relacionado con algún grado de actividad industrial o agro-industrial de carácter capitalista, excluye la actividad artesanal, en la cual proyecto y producción son realizados por la misma persona -actividad que caracteriza a muchas de las economías existentes en Latinoamérica.

Se plantean entonces dos problemas que deben ser dilucidados: primero, la cuestión siempre polémica de cual es, en realidad, el ser de Latinoamérica -si es que tal ser, en su sentido precisamente ontológico, existe- $y$, segundo, en qué categoría encuadrar la ingente producción-ciudades, edificios, utensilios, herramientas, objetos, vestimenta, comportamientos - de los pueblos originarios que se incluyen, incurriendo en un serio error conceptual, en el llamado arte precolombino -como más adelante se verá.

\section{Acerca de Latinoamérica}

La pregunta acerca de qué es Latinoamérica y lo latinoamericano no tiene por ahora una respuesta que dé cuenta cabal, exacta y exhaustiva de la compleja heterogeneidad de factores y acontecimientos que configuran ese magma que se ha convenido en designar con dicho término.

En principio (Valdés de León, 2007) Latinoamérica se define como pura negatividad respecto de "América" (el nombre que los europeos asignaron al "Nuevo" Continente) término que terminó siendo apropiado tempranamente por los Estados Unidos "de América", desde la independencia de las colonias británicas, con arrestos totalizantes y expansionistas: América Latina es lo que no son los Estados Unidos, América Latina es la América que no es anglo-sajona. En consecuencia, lo primero que se destaca positivamente del vocablo es el énfasis semántico puesto en el carácter étnico, por no decir racial ni racista -categorías politicamente incorrectas- del término latino, en oposición al carácter WASP (1) de la América no-Latina. Es sabido que tal denominación no fue producto del pensamiento latinoamericano -si, en efecto, tal categoría existe- sino una construcción europea, producto ideológico de la lucha entre las potencias del Viejo Continente por la hegemonía mundial en la segunda mitad del siglo XIX. Por lo demás, sintomáticamente, el vocablo latino excluye ex profeso a los pueblos originarios de "América" sobre cuyo sustrato, étnico y cultural, Latinoamérica 
ha sido construida. Otras denominaciones propuestas por autores nativos tales como "Hispanoamérica", "Iberoamérica", "Indoamérica", o "Amerindia", cada una de ellas con su correspondiente carga ideológica y una visión particular de la historia, no tuvieron, afortunadamente, mayor fortuna.

En rigor de verdad el único rasgo identitario común de la nación latinoamericana es el carácter mestizo de la mayoría de sus población -y de su cultura- por más que las élites ilustradas de algunas ciudades sudamericanas -en particular Buenos Aires y, con menos pretensiones, Montevideo, capital de la "Suiza de América"- se empeñaran durante mucho tiempo en proclamar un presunto -y presuntuoso- talante europeo, nolatinoamericano: las crisis económicas y políticas de principios de siglo en la Argentina trajeron, entre otras consecuencias, la bolivianización de la arrogante Buenos Aires desnudando su fatal condición sudamericana, su inexorable matriz sudaca.

No está demás agregar que la genealogía mestiza de Latinoamérica ha generado y sigue generando situaciones de tensión nacional y social -que han terminado por naturalizarse- cuando nó de abierta discriminación que no oculta sus raíces racistas. En los países con fuerte presencia de descendientes de los pueblos originarios -en acelerado proceso de aculturización- los sectores mestizos reniegan de sus ancestros indígenas -al extremo que la palabra indio ha tomado la categoría de insulto- al tiempo que dichos sectores, numéricamente importantes, son desvalorizados por las minorías supuestamente blancas, es decir, con un menor grado de mestización, minorías que, generalmente, detentan el poder económico, político y militar. Por otra parte y sobre todo en los centros urbanos tanto blancos como mestizos comparten un común rechazo a negros y mulatos -descendientes americanizados de la gran masa de esclavos capturados a la fuerza en el Africa y trasladados a América para servir en las plantaciones hasta mediados del siglo XIX-así como a las más recientes oleadas inmigratorias de origen asiático.

Inclusive en aquellos países, como la Argentina, en los cuales de importación masiva de europeos se asumió como política de Estado, la afluencia de inmigrantes fue cuestionada por la élites criollas, la oligarquía patricia, - temerosas del carácter plebeyo y contestatario de tal inmigración- acuñándose el término nativismo en oposición a la chusma extranjera y extranjerizante -portadora del virus internacionalista del marxismo o del anarquismo- y cuyos descendientes de primera generación iban a constituir la base electoral -y clientelística- del yrigoyenismo -primer movimiento político popular latinoamericano, madre de todos los futuros populismos.

En las grandes ciudades de los países relativamente más ricos de Latinoamérica que por tal condición, las más de las veces puramente imaginaria, atraen a ciudadanos de países vecinos, relativamente mas pobres, las capas medias locales discriminan a los recién llegados con motes peyorativos y racistas, tales como bolitas, paraguas, chilotes o perucas, expresión lingüística de los profundos sentimientos xenófobos que abrigan importantes sectores urbanos contra sus hermanos latinoamericanos. Esta discriminación adquiere connotaciones clasistas cuando este conjunto -en el cual se incluye a los pobres del propio país- son designados genéricamente como negros villeros -efecto no deseado de la prédica indigenista de fray Bartolomé de Las Casas. Actitud indudablemente racista que está en la raíz de las tendencias nacionalistas y autoritarias, desde la Ley de Residencia y la Liga Patriótica Argentina en adelante. No está demás recordar que, al menos en el Virreynato del Río de la Plata, la Revolución de Mayo, además de representar legítimas reivindicaciones nacionales, fue la resultante de los conflictos de intereses comerciales entre la mayoría criolla y la élite peninsular, a diferencia de la Emancipación Americana que fue el resultado del enfrentamiento de ingleses contra ingleses.

Por otra parte, la expresión "América Latina" al mismo tiempo que exhibe un contenido de orden étnico, como tal cuestionable y conflictivo, oculta al mismo tiempo las condiciones económicas de carácter estructural que marcan de manera indeleble a nuestro continente desde el momento de su descubrimiento. En efecto y a diferencia del tipo de desarrollode las posesiones británicas de Norteamérica, la conquista y colonización de la América Hispánica se concentró en la expropiación violenta de sus riquezas naturales, primero mediante el saqueo de metales y piedras preciosas y mas tarde en la explotación extensiva de la tierra, lo que condujo a formaciones económicas meramente extractivas -el cerro de Potosí, en el Alto Perú, rico en plata de extrema pureza, fue prácticamente trasladado a España para mayor gloria de la Corona- que utilizaban mano de obra esclava o semiesclava gracias a los repartimientos con que los reyes beneficiaban a los colonizadores, hasta concluir con el agotamiento de las minas y una ploblación diezmada.

Esta práctica condujo, ya en período republicano, a la formación de economías primarias de exportación (cereales, ganado, café, frutas tropicales, añil, maderas, café, metales, etc.) muchas de ellas basadas en el monocultivo que, al tiempo que satisfacían las demandas alimentarias y de materias prima de los países industrializados imposibilitaron por siglos el surgimiento de formaciones económico-sociales modernas, de proyectos industriales capitalistas y, consecuentemente, de mercados internos sustentables y burguesías nacionales dinámicas y progresistas. Cada locomotora que se importaba del Reino Unido, con alto valor agregado de tecnología y diseño, que para los ilustrados del sigloXIX representaba el acceso al progreso y la modernidad, retrasaba por años la instalación de industrias siderúrgicas y metalúrgicas en nuestros países -y el desarrollo de la ingeniería y del Diseño industrial, innecesarios para esta lógica económica. Cada corte de casimir inglés -por lo demás manufacturado con materia prima local-importado junto con los correspondientes figurines postergaba por decenios el surgimiento de la industria textil y de un diseño de indumentaria con rasgos nacionales. Las mismas prácticas regresivas se pueden verificar en las distintas ramas de la economía, hasta hoy: en la Argentina, aprovechando una coyuntura mundial favorable la oligarquía rural exporta masivamente soja obteniendo enormes beneficios, como contrapartida, el país debe importar la tecnología digital, con mucho más valor agregado, indispensable para su funcionamiento.

Recién en el período de entreguerras del siglo XX y como efecto de la crisis mundial del capitalismo se da inicio en algunos países (Argentina, Brasil, México, entre otros) a procesos de industrialización por sustitución de importaciones que, en algunos casos, tuvieron continuidad en el tiempo al amparo de gobiernos con vocación nacional-tachados, por supuesto, de populistas. La Revolución Industrial, causa y efecto del Diseño moderno, llegó tarde y mal a Latinoamérica, lo que explica -junto a otros factores concurrentes- su atraso respecto a los modelos económicos y políticos europeos: más que una cuestión coyuntural, o peor aún, cultural, el subdesarrollo latinoamericano tiene su origen en una historia devenida estructura: la expropiación salvaje de las riquezas de "Las Indias" -que no eran inagotables- contribuyó estratégicamente -la acumulación originaria- al financiamiento del capitalismo industrial europeo, al precio de imposibilitar en la práctica el desarrollo de economías capitalistas modernas en nuestros países. 
Este atraso estructural, que determina un atraso correlativo en las disciplinas proyectuales, también está relacionado, siguiendo a Max Weber (1969) con los principios ético-religioso, radicalmente diferentes, que legitimaron los procesos colonizadores en Norteamérica, por un lado, y la América hipánico-portuguesa, por el otro. La ética protestante fomentaba el afán de lucro de las burguesías anglosajonas, presentando el trabajo como un deber cristiano pero limitando el disfrute de su producto, destinando parte de éste al ahorro, propiciando de esta manera la acumulación de capital. Contrariamente la ética del catolicismo de la Contrarreforma -hegemónica en todo el período de la conquista y colonización- privilegió los aspectos espirituales, postulando la pobreza como virtud evangélica (es mas fácil que un camello entre por el ojo de una aguja a que un rico entre en el Reino de los cielos) y demonizando la posesión de bienes materiales, convertida en pecado, al mismo tiempo que acumulaba para sí una enorme riqueza ad majorem gloriam Dei.

\section{Resistencia e hibridación}

Las sociedades originarias, su cultura y su diseño -que había alcanzado un nivel comparable al contemporáneo medioevo tardío europeo,(el arte en este contexto es un concepto anacrónico)fueron brutalmente destruidas, barbarizadas y fragmentadas por la civilización occidental y cristiana, representada por los Conquistadores, a partir de 1492, quienes con el recurso de su mayor poderío militar impusieron por la fuerza sus valores y creencias a los pueblos originarios -ése Otro absoluto para la mentalidad dominante- que fueron privados, incluso, de su condición humana, reducidos a simples objetos de uso: sus instituciones políticas fueron desmanteladas, el tejido social destrozado y su cultura convertida en barbarie (aún faltaban varios siglos para que la Europa imperialista inventara la moderno Antropología). Como los restos profanados de un espejo roto los sobrevivientes de ese mundo originario que nunca tuvo nombre propio, los sobrevivientes del primer Holocausto de la historia moderna (los cálculos mas conservadores estiman en cerca de 50 millones las muertes causadas por la violencia imperial durante la conquista) se refugiaron en las comunidades locales -y en en su interior anímico y lingüístico- iniciando el largo proceso de hibridación que marca nuestra historia.

La única forma viable de resistencia social consistió, entonces, en la aceptación formal de los rituales, verbales y conductuales, impuestos coercitivamente por la Iglesia y la Corona, dando lugar al sincretismo cultural que caracteriza a Latinoamérica: asumir en la exterioridad como propias las conductas sociales impuestas por el invasor, tratando de mantener vivas las tradiciones ancestrales, adaptadas a las circunstancias de la dominación. Mas tarde, con la introducción masiva de esclavos africanos para el trabajo en las plantaciones, aquellos que sobrevivieron a las penurias del viaje, al desarraigo, al sadismo de los esclavistas y a las nuevas y desconocidas enfermedades introducidas por los blancos, pusieron en práctica la misma estrategia de supervivencia: las antiguas divinidades se fueron transmutando en figuras del santoral católico, los ritos ancestrales se mimetizaron en las nuevas ceremonias religiosas, como la única manera de mantenerlos vivos en el imaginario social. Aunque pueda resultar desagradable, la cultura Latinoamericana es el producto inestable de los pueblos vencidos que pudieron sobrevivir a la catástrofe de la Conquista, en otras palabras, nuestra cultura es producto de de la violencia de los conquistadores extranjeros y su consecuencia, el mestizaje.

México y Lima, las grandes ciudades coloniales de la América Hispana (que todavía no era Latina) fueron construidas imitan- do los estilos dominantes en los centros urbanos europeos adaptados a las nuevas circunstancias geográficas y humanas. Las técnicas, las estéticas y, en ocasiones, los materiales mismos, fueron importados de Europa. Todavía en el siglo XIX en las modernas ciudades emergentes, como Buenos Aires, se importaban también arquitectos extranjeros para el diseño y construcción tanto de mansiones privadas como de obras públicas, los que introdujeron las tendencias historicistas y neo-clasicas $-y$, ya en el siglo $X X$, el estilo internacional del Movimiento Moderno.

El Diseño del período colonial se define por su hibridez; la conjunción, aleatoria, de la impronta proselitista de la Contrarreforma con los remanentes de las culturas originarias dio como resultado una versión, propia americana, o mejor, indiana, del Barroco y el Rococó, presente tanto en las arquitectura y la escultórica de El Aleijadinho (Antonio Francisco Lisboa) en el Brasil, como en la escuela musical que floreció en las Misiones Jesuíticas, con epicentro en Chiquitos, en los "ángeles arcabuceros" de la escuela de Potosí (ambos en el Alto Perú) y en el fastuoso esplendor visual de las catedrales que enjoyaron las principales ciudades de los Virreynatos de Nueva España y del Perú, lujosamente ornamentadas; las prescriptivas renacentistas se funden, no necesariamente de manera armónica, con las milenarias tradiciones locales creando un estilo de caracteristicas específicamente americanas.

La tensión entre lo autóctono y lo exógeno (en Latinoamérica lo verdaderamente exótico es lo europeo), entre tendencias centrípetas y centrífugas, entre lo auténtico y lo imitado, entre la barbarie y la civilización, y como resultante, la hibridez conceptual y formal, definen desde sus orígenes al Diseño Latinoamericano: su enorme riqueza en la cual finca su identidad es también la causa de los obstáculos, a veces insalvables, que se presentan al momento de pretender establecer tipologías y categorías de análisis que instauren un cierto orden sobre tal heterogeidad: igual que ocurre con Latinoamérica, que le ha dado origen y tallado su multiforme fisonomía, el Diseño Latinoamericano se torna inasible en su misma multiplicidad, transmutándose en mito.

\section{La época moderna: de la resistencia a la imitación}

La modernidad, por razones que se ha intentado explicar, llegó tardíamente a Latinoamérica y no a todos los países por igual; incluso en sus regiones mas deprimidas no ha llegado aún, ni lo hará, presumiblemente, en el futuro próximo. Sin embargo, sobre estructuras económicas precapitalistas-coexistencia de grandes latifundios explotados mediante el empleo de mano de obra servil o semi servil con minifundios de mera subsistencia, escaso o nulo acceso de grandes masas a la alfabetidad y a la escolarización, economías urbanas informales, raquitismo de las burguesías nacionales- se han ido estableciendo formas de comunicación y socialización típicas del capitalismo tardío: la Globalización económica y los hábitos culturales posmodernos han acelerado el proceso histórico de hibridación, cada vez mas volcada a la mera imitación y cuyo paradigma actual es la Internet, aún cuando del total de usuarios de la red apenas el 3,2 \% corresponde a América Latina y el Caribe. (Bernardo Kliksberg, asesor del PNUD para América Latina, en Clarín 11/7/07) -en un continente en el cual, según la misma fuente "mas de 50 millones de jóvenes latinoamericanos están fuera del sistema educativo y del mercado de trabajo."

En los países relativamente mas avanzados (Brasil, México, la Argentina, Chile) el Diseño moderno como subproducto (y causa al mismo tiempo) de la Revolución Industrial primero y de las 
llamadas vanguardias artísticas después, es decir, como subproducto de la cultura europea, se ha consolidado como práctica social especializada, alcanzando incluso el estatus de disciplina universitaria, muchas veces bajo la égida de la Arquitectura. No puede entonces sorprender que el Diseño moderno desde su origen haya sido construído en Latinoamérica a partir de la imitación, a veces oportunista, otras por mera casualidad, de los estilos europeos contemporáneos. La aplicación de esta política de imitación se verifica en los mas diversos ámbitos. Así, a fines del siglo XIX cuando la República Argentina había completado su inserción como país agro-exportador en la economía mundial, su Ejército adopta para la formación de sus cuadros el modelo militar prusiano por su eficacia y modernidad-decisión que acarreará dificultades políticas al estado argentino en el período de la Segunda Guerra Mundial-; las estaciones ferroviarias, los barrios aledaños y muchas de las fábricas de los años 30 se construyen siguiendo los modelos ingleses; el incipiente Diseño gráfico de mediados del siglo XX adopta como modelo el Estilo Tipográfico Internacional o Escuela Suiza. Y cuando, en la década de los 80, el Diseño alcanza estatus universitario los flamantes docentes -arquitectos reciclados a la gráfica, artistas plásticos, dibujantes publicitarios, fotógrafos, idóneos autodidactos, licenciados en disciplinas humanísticas- tienen que resolver la urgente cuestión de la enseñanza-aprendizaje del Diseño recurren al expediente de transpolar -de manera mecánica y acrítica y sin reparar en la radical diferencia entre los respectivos contextos- los ya anacrónicos métodos implementados en la época de la República de Weimar por la Staatliches Bauhaus, a los que agregarán los aportes de la Hochschule für Gestaltung de UIm -que había sido justificadamente cerrada por decisión del Consejo de Baden-Württemberg... veinte años atrás.

De la misma manera, la orfandad teórica de las nuevas carreras fue solventada echando mano al corpus teórico de las tendencias predominantes en los países centrales,

tomadas y reproducidas, en general, con considerable atraso: los métodos racionalistas y funcionalistas del Movimiento Moderno, adecuadamente sazonados con los arrestos revolucionarios de las vanguardias, los dogmas estructuralistas, la semiótica -o la semiología, como mas convenga a la ocasión-, el constructivismo, pero también el deconstructivismo, la teoría comunicativa del producto -traducida aquí como SP o semántica del producto-, la hermenéutica, la holística, los post estructuralismos, las lábiles propuestas posmodernas- y la enumeración podría continuarse- se van sucediento eclécticamente como paradigmas discursivos destinados a cubrir, precariamente, aquella orfandad -a falta de un vigoroso pensamiento propio situado con firmeza en la problemática latinoamericana. E espíritu de imitación de los estilos de pensamiento foráneos, presente desde la Colonia, sigue siendo hasta hoy un rasgo, entre otros, de la cultura latinoamericana -y . por lo tanto, del Diseño y de la reflexión sobre su práctica.

\section{Avatares del Diseño Latinoamericano}

Considerando la complejidad del conglomerado de hechos y situaciones que entraña la cuestión Latinoamérica, hasta aquí apenas esbozada, la cuestión de la existencia -empírica y teórica- de un Diseño Latinoamericano es tan conflictiva y contradictoria como Latinoamérica misma y, como ésta, ha accedido a la condición de mito.

Como hecho empírico al Diseño Latinoamericano consistiría en la colección, heteróclita, dispersa, innumerable, de todos los objetos diseñados y producidos en el interior del espacio geográfico y político que se designa convencionalmente como
Latinoamérica, dentro de límites temporales que pueden ser periodizados de diferentes maneras -incluyendo en dicha colección la rica producción artesanal.

Ello no significa que, mas allá de su común ubicación espaciotemporal, tal colección de objetos se presente a la mirada del investigador como un conjunto ordenable que responda a determinados patrones conceptuales y formales y a modalidades compartidas de uso capaces de otorgarle una cierta organicidad. Por el contrario, y a esto contribuye la precariedad teórica lamentablemente consubstancial a la disciplina, el Diseño Latinoamericano no constituye un objeto de estudio claro y preciso, tanto en sus contenidos como en su temporalidad, pasible de ser abordado con herramientas (perdón, la palabra está de moda) conceptuales consensuadas científicamente.

Desde el planteo mismo del problema se hace notar la presencia de términos equívocos o polisémicos que no son, sólo, producto de la general ignorancia sobre Latinoamérica -ignorancia que se presenta como sentido común- sino, mucho peor, de conocimientos utilizados en función ideologizante, Veamos, entonces, algunos de los avatares del Diseño en nuestro continente.

El Diseño, tal como lo hemos descripto, ha existido como práctica individual y social desde que América existe. Ahora bien, ¿desde cuándo existe América?

Gracias a la Arqueología es un hecho probado la existencia de sociedades organizadas con un alto grado de sofistificación cultural, implantadas en regiones del centro y el sur de nuestro continente por lo menos desde 2000 años ANE. La producción de objetos de diseño, es decir, artefactos útiles tanto por sus prestaciones funcionales como simbólicas

en la vida cotidiana de los pueblos originarios -remotos descendientes de las oleadas migratorias que llegaron a éste continente, vía estrecho de Behring, hace por lo menos 45.000 años según las hipótesis mas creíbles- cubre todo el espectro de las necesidades prácticas de sociedades complejas y organizadas: las monumentales cabezas esculpidas en piedra de la cultura olmeca, las pirámides escalonadas de Teotihuacán, los estadios para el ritual juego de pelota, el centro ceremonial maya de Chichén Itzá (designado Nueva Maravilla del Mundo, según la reciente y publicitada encuesta organizada vía Internet por la Fundación New 7 Wonder) y de Tikal, entre otras, los frescos de Bonampak (también de origen maya), las gigantescas instalaciones líticas del Macchu Picchu (también proclamado Maravilla del Mundo según la encuesta antes citada), las estelas talladas de Quiriguá y Copán, los sistemas de sembradío en terraza de los agricultores incas, además de la inabarcable cantidad de prendas, herramientas, utensilios y objetos destinados al adorno personal, a los rituales religiosos y al uso cotidiano, así como los sistemas protoescriturales -glifos, códices, quipusconstituyen la irrevocable demostración material de la existencia de un Diseño originario, funcional a las demandas de aquellas sociedades.

No obstante, este vasto conjunto de centros urbanos, edificaciones, artefactos y comportamientos ha sido relegado, no inocentemente, en los museos y en los textos, a la innocua categoría de arte precolombino, con lo cual todos estos objetos, diseñados en función de concretas demandas sociales, terminan convertidos en obras de arte aptas únicamente para la contemplación hedonista y el placer estético, desgajadas de la trama social que les dio origen, uso y sentido. El mismo término (precolombino) resulta inadecuado en tanto otorga existencia fáctica a los pueblos originarios y a su cultura en virtud de haber sido descubiertos por Colón, acontecimiento sin el cual no existirían -al menos para la mirada europea que, con este 
expediente, al descubrirlos, autoriza su ser incorporándolos a la Historia. En realidad, las culturas originarias fueron incorporadas, con una fuerte carga negativa, al imaginario occidental después de Colón, por lo que resultaría más razonable designarlas post colombinas. (2)

Los objetos de este primer diseño elaborados con materiales preciosos -oro, plata, pedrería- fueron de inmediato rapiñados por los conquistadores ávidos de fáciles riquezas; aquellos que sólo poseían valor simbólico fueron destruidos por el fanatismo militante de los frailes de la Contrarreforma -que legitimaron, como muchos integrantes de la Iglesia en los años del Proceso an la Argentina de los 70, la rapiña y el exterminio físico del diferente-considerándolos expresiones de idolatrías diabólicas, opuestas a la verdadera religión.

Hasta donde sabemos las culturas originarias no tuvieron, ni podían tener, conciencia de su origen común; a la llegada de los conquistadores las organizaciones político-religiosas mas importantes, aztecas e incas, sólo tenían una implantación territorial limitada, sin contactos recíprocos ni conciencia alguna de orden continental (esto es, en términos actuales, americano). La utopía americanista aparecería mucho después.

En síntesis, el Diseño Latinoamericano en sus orígenes históricos ni fue latino ni fue americano: aunque suene paradojal, el Diseño latinoamericano, como ahora se entiende dicho término, es anterior a la propia existencia de América Latina.

\section{Diseño y realidad nacional}

Muchos de nuestros países calificados como subdesarrollados, -o más cínicamente, en vías de desarrollo- arrastran el lastre de economías precapitalistas, con importantes masas rurales, y también urbanas, no integradas al mercado del trabajo y el consumo ni a las instituciones formales de la democracia representativa; en tales sociedades el Diseño no pasa de ser un veleidad cultural de las élites de los centros urbanos, un símbolo más de su poder económico y político. Como contrapartida, en aquellos países en los cuales se han desarrollado importantes núcleos industrializados (San Pablo, Río de Janeiro, México D.F., Monterrey, Buenos Aires, Córdoba, entre otros) que han accedido a la modernidad capitalista, la función del Diseño deviene estatégica como factor dinamizador del crecimiento.

No obstante, en estos focos modernizadores coexisten, dentro de su propio país -y aún dentro de si mismos- con bolsones, o cinturones, de pobreza formados por millones de ciudadanos que han sido excluidos del mercado. La heterogeneidad -económica, social, política y cultural- de nuestra América, consecuencia de procesos de desarrollo desiguales e inequitativos, ha fomentado la fragmentación interna y dificultado la consolidación de identidades nacionales fuertes, proceso que se ha visto agudizado por el impacto agresivo de la Globalización asimétrica y la implementacion de políticas económicas neoliberales. El resultado es la polarización creciente entre minorías privilegiadas que disfrutan de un alto estandar de consumo y mayorías marginadas que sobreviven, como pueden, bajo la así llamada línea de pobreza que en algunos casos, como en el de Perú, afecta a mas del $60 \%$ de la población, no obstante el sostenido crecimiento macroeconómico experimentado por dicho país.

Una manera de graficar las dificultades de orden metodológico que presenta la cuestión del Diseño Latinoamericano y, al mismo tiempo, ilustrar los enunciados anteriores, será intentar un análisis sumario de un caso particular, el del diseño argentino En strictu sensu la expresión diseño argentino se refiere a un conjunto de prácticas de diseño que, por su carácter disperso, inorgánico y contradictorio harían sumamente difícil, cuando no imposible, establecer rasgos comunes que otorguen a dicho conjunto un grado mínimo de inteligibilidad. Caben, entonces, dos posibles respuestas:

a) Designar como diseño argentino a todos los objetos diseñados y producidos en el territorio físico que históricamente se designa como República Argentina, cualquiera sea su índole y sus modalidades de producción -remontándonos en el tiempo, por lo menos, hasta 1816. En este caso el único rasgo común de esta producción no sería otro que la incómoda pertenencia a un sujeto político y geográfico. Y poco más que eso.

b) Designar como diseño argentino exclusivamente al que se produce con métodos y sistemas modernos en aquellos centros urbanos industrializados que son, a la vez, centros administrativos y políticos, es decir, Buenos Aires y su conurbano, con algunas concesiones, políticamente correctas, a prácticas puntuales de diseño localizadas en el "Interior" del país que proveerían al conjunto selecionado de un no desdeñable color local, tan caro al eclecticismo multicultural de la estética posmoderna.

Por supuesto que las dos respuestas sería incorrectas; una por extremadamente amplia y poco precisa, la otra, por el contrario, por excluyente y localista. ¿En dónde ubicar, entonces, a nuestro elusivo diseño argentino? ¿Pertenecen al mismo conjunto el Rastrojero -ícono de la ingeniería y el diseño industrial avant la letre argentinos-, el estilo fashion de los modistos de Recoleta, las tapas de los libros del Centro Editor de América Latina de la década de los 80 y la producción artesanal del NOA?

Pero si nos ceñimos al caso particular de Buenos Aires, históricamente cosmopolita y europeizante, observamos que en los medios suele denominarse diseño a cualquier actividad, -incluso de carácter artesanal (prendas de firma)- que coduzca a laproducción de objetos destinados a satisfacer las, supuestas, demandas de figuración, esto es, de imagen, de las clases medio-altas con poder adquisitivo y, no menos supuesto, sofisticado nivel cultural, utilizándose, para caracterizarlo, términos como diseño joven, creativo, vanguardista, posmo, cooly, por supuesto, fashion.

Este diseño, que se consume y exhibe respetando determinados rituales en pequeños pero dinámicos guetos urbanos (Palermo Hollywood, Palermo Soho, Recoleta, Puerto Madero) es radicalmente otro al que se poduce y consume, -sin ir mas lejos, literalmente- en la Villa 31 o en la 1-11-14, ésta última estigmatizada como reducto de narcotraficantes peruanos (incluso como sucursal de San Juan de Lurigancho, el populoso barrio limeño) por la mirada sensacionalista de los medios.

Es importante destacar que desde los mismos nombres con que referencian, estas tendencias de diseño se automarginan con respecto de su propio país, identificándose imaginariamente con lugares exóticos que han adquirido valor de símbolo universal (Hollywood, la fábrica de sueños). La vocación mimetizadora conduce a la marginación deliberada, en tanto a escasas cuadras otros marginados producen y viven valores culturales radicalmente diferentes y antagónicos, al extremo de ser tachados de extranjeros. La búsqueda de las raíces ancestrales que proponía lúcidamente en 1970 Piero Maria Bardi, director del Museo de Arte de San Pablo como una alternativa fértil para el Diseño (según Satué, Enric, 1998) ha sido sustituida por la superficialidad oportunista del pastiche posmoderno: de allí el surgimiento de tendencias de diseño de nombres imposibles 
pero de fácil repercusión mediática como telúrico fashion, cosmo fashion o gaucho look.

Estas prácticas de diseño que, suponemos, tienen equivalentes locales en otras ciudades de nuestra América, existen a espaldas del país pero, no obstante, forman parte de su cultura -y de la de Latinoamérica- en tanto expresión de una condición colonial y de subordinación a la potencia imperial de turno y de los efectos ideológicos de esta subordinación en las identidades nacionales: en este sentido, Latinoamérica es, en gran parte, el reflejo de la imagen que Occidente tiene de Latinoamérica.

\section{Desconocimiento recíproco}

Otro factor que siempre ha conspirado contra una articulación orgánica del Diseño Latinoamericano es el desconocimiento recíproco entre quienes practican la disciplina y el desconocimiento general de la producción teórica y práctica de Diseño que se realiza en el resto de los países -e, incluso, en el propio país. Este desconocimiento no es privativo del Diseño, lamentablemente se replica en el conjunto de las artes y la cultura latinoamericana-que terminan siendo palabras vacías de contenido. A excepción de un escaso número de figuras que han alcanzado reconocimiento internacional (los muralistas mexicanos, Frida Kahlo, Rufino Tamayo, Osvaldo Guayasamín, Wilfredo Lam, Fernando Botero o Joaquín Torres García, por mencionar algunos) el grueso de la producción plástica latinoamericana generalmente no trasciende los estrechos límites del ámbito local o nacional: ¿existen pintores importantes en El Salvador o Paraguay?

En el campo de la música clásica latinoamericana la situación no es mejor: las obras de Silvestre Revueltas, Carlos Chávez, Ernesto Lecuona, Heitor Villa-Lobos o Alberto Ginastera, por mencionar sólo a algunos de los autores mas conocidos en este género, casi no se interpretan fuera de sus respectivos países y sus grabaciones son difíciles de encontrar: ¿existen músicos académicos importantes en Honduras o Bolivia?

Lo mismo ocurre con los autores que desde diferentes perspectivas y experiencias han ido construyendo lo que puede llamarse pensamiento latinoamericano. Limitándonos siempre al siglo XX las obras de Juan José Hernández Arregui, Alcides Arguedas, Darcy Ribeiro, Joaquín Edwards Bello, German Arciniegas, Vicente Sáenz, Benjamín Carrión, Arturo Masferrer, Juan José Arévalo, Vicente Lombardo Toledano, Rafael Barret, Juan Carlos Mariátegui, Eugenio María de Hostos, Pedro Henríquez Ureña, Carlos Vaz Ferreira o Rufino Blanco Fombona, entre muchísimos otros, no son leídas -a veces ni siquiera conocidas- mas allá de sus países, salvo por los especialistas en estudios latinoamericanos. (Los autores mencionados y muchos más, pueden ser consultados en Piñeiro Iñíguez, Carlos, ob. cit.) Sus nombres nunca figuran en las bibliografias de los papers de los escasos estudiantes de Diseño que abordan problemáticas latinoamericanas, bibliografías -en cambio- copiosas de referencias a Barthes, Baudrillard, Deleuze, Eco, Foucalt, Lacan, Lipovetzky, Lyotard. Bourdieu, Berman o Nietzsche. Para poder legitimar un texto propio ¿es indispensable citar a autores europeos de moda? ¿Latinoamérica nunca se ha pensado a sí misma? (3)

Como es natural -y de manera simétrica- en los textos europeos de Diseño Latinoamerica directamente no existe. En el sintético compendio de Richard Hollis (1994) que describe el desarrollo del Diseño gráfico en el mundo desde 1860 hasta finales del siglo pasado, entre cerca de 500 nombres mencionados en el texto figura sólo un latinoamericano, el cubano Félix Beltrán. En el, más ambicioso, trabajo de Philip B. Meggs (2000) la situación es parecida, de un total de cerca de 900 entradas del Indice, -que incluye, por ejemplo, el cartel en Sudáfrica- apenas media docena se refieren a autores latinoamericanos: Eduardo Terrazas y Manuel Villazón por su participación en el equipo liderado por Lance Wyman que diseñó la imagen de los Juegos Olímpicos de México en 1968; Raúl Martínez y Elena Serrano, como autores de afiches en defensa de la Revolución Cubana y José Salomé Gómez Riveria por un cartel para el Ejército Popular Sandinista. Se mencionan además, pero por otros motivos, a Fidel Castro, Ernesto "Ché" Guevara y Pablo Neruda, pero se omite, llamativamente, a Félix Beltrán. Del resto, silencio. Pero, ¿hay resto? ¿Existe algo parecido al Diseño gráfico en el Ecuador o Costa Rica?

Más generoso, Enric Satué (1998), que escribe directamente en castellano, dedica un capítulo de su obra al Diseño gráfico en América Latina, en el cual describe sintéticamente el origen y el estado de situación de la disciplina en Colombia, Perú, Venezuela, Chile, México, Cuba, Argentina y Brasil, mencionando una treintena de nombres entre los cuales destacan autores tan distantes en tiempo y estilo como José Guadalupe Posada y Leopoldo Méndez -en realidad, más que gráficos, eximios grabadores- Félix Beltrán y Juan Carlos Distéfano. A excepción de estos nombres -y los de Eduardo Giménez y Raúl y Ronald Shakespeare- el resto de los gráficos nombrados, que sería ocioso reproducir aquí, son prácticamente desconocidos fuera de sus países, lo que confirma la tesis expuesta en este trabajo. El texto de Satué deja la impresión de que la información de la que dispuso no estuvo suficientemente actualizada, de allí que subraye aquellas coyunturas en las que el Diseño gráfico, por circunstancias políticas, -hoy devenidas históricas-alcanzó protagonismo nacional e internacional al asumir un papel decididamente revolucionario: la Revolución Cubana (de nuevo Beltrán, hasta su exilio en México), el gobierno de la Unidad Popular en Chile, la fallida experiencia del Sandinismo en Nicaragua, y, ya en otro registro, la época de experimentación del Instituto Di Tella en la Argentina de los años 60.

De todos modos el diagnóstico de Satué sobre la gráfica latinoamericana no es particularmente auspicioso. Con referencia a México sostiene:

Como en el resto de América Latina -y en cierto modo como en el resto del mundo llamado occidental- sigue imperando en el campo publicitario mexicano el modelo americano (por norteamericano, V.de.L. G.A.) más estereotipado, al que hay que obligarse, simplemente, a copiar. (Ob. cit. p. 405)

Salvo el caso de Posada y de algunos otros pioneros del siglo XIX, del texto de Satué se desprende que el Diseño gráfico recién empieza a adquirir carta de ciudadanía en Latinoamérica a mediados del siglo pasado, en general subordinado a las agencias de publicidad -las mas importantes, de capital norteamericano.

Además, como no podía ser de otra manera, la tendencia dominante en la recién nacida disciplina fue la ya conocida compulsión a la imitación de las escuelas europeas supuestamente prestigiosas y modernas. En el caso del Brasil tal tendencia se autodesignó como "Ulmismo" -obvia referencia a la HfG Ulm-, irónicamente definida por el ya citado Piero Maria Bardi, en 1970, como una enfermedad que trajeron los artistas que fueron a UIm tratando de transplantar el glacial clima de las montañas europeas al Trópico de Capricornio. (Satué, ob. cit. p. 431.) Bardi, otro de los desconocidos de siempre plantea con lucidez la contradicción principal que atraviesa la cultura brasileña -pero también la cultura latinoamericana, y el Diseño- entre quienes tratan de introducir las últimas novedades extranjeras, 
adaptándolas a su cultura bajo una capa de barniz nacional y quienes empeñosamente bucean en la profundidad del arte nacional popular tratando de unir las formas actuales a raíces ancestrales todavía sin forma (Satué, Ob. cit. p. 431).

\section{Programa hasta hoy no concretado}

La ausencia de instituciones que representen de manera legítima, eficaz y operativa a los diseñadores (en Buenos Aires, a mas de 20 años de inauguradas las carreras de Diseño bajo la férula de la Facultad de Arquitectura de la UBA no existe ninguna asociación gremial que nuclée a los egresados), la escasa cantidad de publicaciones especializadas, la efímera existencia de muchas de ellas, su nula difusión a nivel continental, son algunos de los síntomas del desconocimiento recíproco que venimos analizando: ¿se sigue publicando Magenta, revista de diseño, fundada en Guadalajara, México, en 1983 por el grupo Arco Iris? ¿Se sigue editando Gráfica, que dirigía en Brasil Osvaldo Miranda ? Y si así fuere siguen siendo desconocidas por los diseñadores del resto de Latinoamérica. ¿Cuál fue el destino final de Tipográfica? ¿Existen otras publicaciones de diseño en nuestro continente o la única que ha logrado perdurar es El Gráfico que, como todos saben, a pesar de su nombre nada tiene que ver con nuestra disciplina?

Por otra parte es notoria la ausencia casi total de muestras y exposiciones que permitan a los diseñadores y al público de un país entrar en contacto vivo con el pensamiento y la producción gráfica de los otros países de la región. En Buenos Aires una de las exposiciones de diseño mas publicitada y visitadas fue la organizada hace muchos años para homenajear a la Bauhaus -para entonces ya definitivamente fosilizada-; más recientemente se realizó una muestra de las Vanguardias Rusas y muy poco más De Diseño argentino, nada -ni hablar de Diseño Latinoamericano. En su defecto se multiplican las ferias y festivales de diseño con fines estricamente comerciales, aderezados con los rituales fashion, a la manera de shoppings de diseño.

En la década del 80, en circunstancias políticas adversas (todavía imperaba en el país la Dictadura Militar), la entonces pujante ADG (Asociación de Diseñadores Gráficos de Buenos Aires) con la colaboración de ICOGRADA (4) logró montar en las instalaciones del Museo de Arte Moderno de Buenos Aires, la Primera Exposición Nacional e Internacional de Diseño Gráfico -hasta ahora la única- y en los años siguientes, junto con la publicación de Anuarios financiados por sus socios - que alcanzaron 5 ediciones consecutivas- organizó sucesivas exposiciones de la producción local, con gran convocatoria. Lamentablemente, al desaparecer aquella institución, corroída por mezquinas rencillas intestinas, las exposiciones y las publicaciones dejaron de realizarse.

En suma, carencia de organizaciones representativas y estables; inexistencia de publicaciones locales o nacionales que promuevan el diálogo y el debate sobre la práctica y la teoría del Diseño; desinterés -cuando no, desidia- de los organismos públicos municipales y nacionales por el desarrollo de la disciplina, -consecuencia de la ignorancia de los funcionarios respecto de la potencialidad innovadora del Diseño-; ausencia casi absoluta de estímulo a programas de investigación y proyectos de experimentación por parte de las instituciones de enseñanza públicas y privadas, salvo escasas y honrosas excepciones; desconocimiento generalizado de los medios de difusión acerca de qué es efectivamente el Diseño, lo que ha instaldad en el público una imagen degradada de la profesión, asociada a la efímera frivolidad de las modas y las ondas; son todos factores que inciden negativamente y convergen en el síndrome de desconocimiento recíproco que hemos intentado describir -y que dificultan la institución del Diseño Latinoamericano como objeto digno de estudio.

\section{A manera de conclusión}

En tanto los practicantes de las distintas disciplinas del Diseño continúen dispersos e incomunicados, cada uno refugiado en el confortable y estéril aislamiento del estudio o la cátedra, disfrutando del módico reconocimiento local, indiferente a su condición latinoamericana, la construcción de un proyecto de Diseño Lationamericano no pasará de ser otra vaga e inútil utopía.

Envuelto en una nebulosa de desconocimiento general, el Diseño Latioamericano ha ido asumiendo la forma, muy nuestra, de mito que, como tal, debe ser cernido por la razón y la ciencia, mediante un abordaje trasdisciplinarm dentro de una perspectiva antropológica y con rigor metodológico -sin que ello implique renuncia alguna a esa necesidad de infinito que proclamaba Mariátegui, incumbencia exclusiva del arte y la filosofía.

En primer lugar se debería realizar un inventario -ponderado, no exhaustivo-, en el interior de cada país y dentro de límites temporales definidos, del conjunto de objetos producidos mediante operaciones de diseño, estableciendo con claridad los criterios de pertinencia que marquen con precisión qué productos deben ser incluidos legítimamente en este inventario, diferenciándolos de los objetos artísticos o artesanales.

En esta etapa se deberá prestar especial atención a aquellas expresiones que han logrado incorporar en el proceso de diseño, con mayor o menor fortuna, las tradiciones locales, mestizas a las tecnologías y estéticas de carácter internacional de la Modernidad, explicitando aquellos patrones -conceptuales, formales, conductuales- que otorgan al conjunto inventariado una inequívoca identidad nacional -si tales patrones existieren.

En una segunda instancia el material relevado, ordenado por países, debería ser examinado para establecer la existencia de rasgos compartidos que evidencien efectivamente su identidad latinoamericana.

Un programa de estas características, que implica el esfuerzo de equipos capacitados y una programación a mediano plazo, sólo puede ser encarada y gestionada por aquellas instituciones -educativas, profesionales, gubernamentales- comprometidas con el Diseño y que estén convencidas de que ésta investigación es urgente y necesaria. Aún cuando los primeros resultados sea incompletos y fragmentarios, se habría iniciado un proceso de reconstrucción e interpretación que, en algún momento, nos develará el verdadero rostro, por ahora inasible, del Diseño Latinoamericano

La realización, por segunda vez consecutiva, del Encuentro Latinoamericano de Diseño, convocado por la Facultad de Diseño y Comunicación de la Universidad de Palermo y la publicación de Actas de Diseño en las cuales, por primera vez, se reúnen trabajos de académicos y profesionales de diversos países de nuestro continente, constituye por ahora el proyecto institucional mas auspicioso en relación con nuestro tema; esperando que la continuidad de este emprendimiento conduzca a la creación de formas organizativas que perduren en el tiempo.

Ahora, mas que nunca, otro diseño es posible en una Latinoamérica que está encontrándose con su destino. 


\section{Notas}

1 Siglas de White Anglo-Saxon Protestant, como características identitarias del norteamericano "puro".

2 En rigor, Cristóbal Colón nunca "descubrió" América. El tozudo Almirante de la Mar Océano murió convencido que había "descubierto" el extremo occidental -para los europeos- de "Las Indias": de allí la denominación impuesta a los habitantes del Nuevo Continente, indios, que aún perdura.

3 No se trata de oponer autores extrajeros contra autores locales -expresión, quizá, de velados sentimientos de inferioridad- sino, por el contrario, de incorporar (literalmente) -en la medida en que ello sea posible- todo lo positivo, por no decir "alimenticio", del pensamiento progresista europeo e internacional, pero desde nuestra peculiar e irrenunciable situación latinoamericana.

4 Siglas del International Council of Graphic Design Associations.

\section{Bibliografía}

Hollis, R. (1997). Graphic Design, a concise history, London: Thames and Hudson. Versión en castellano (2000) El Diseño Gráfico. Una Historia abreviada. Ediciones Destino. Barcelona.

Meggs, P. B. (1998). A History of Graphic Design. John Wiley \& Sons. Versión en castellano (2000) Historia del Diseño Gráfico, México: McGraw-Hills.

- Piñeiro Iñíguez, C. (2006). Pensadores Latinoamericanos del siglo XX Ideas, utopía y destino, Buenos Aires: Instituto Di Tella-Siglo XXI.

- Satué, E. (1998). El diseño gráfico. Desde los orígenes hasta nuestros días, Madrid: Alianza Editorial.

- Valdés de León, G. A. (2007). "Ni Macondo ni Macdonalds: otra América es posible" en Actas de Diseño 2, Buenos Aires: Facultad de Diseño y Comunicación. Universidad de Palermo.

- Weber, M. (1969). La ética protestante y el espíritu del capitalismo, Barcelona: Península. 